\title{
La representación del Tormentum Rotarum de Santa Catalina en la iglesia de San Sebastián de las Carreras de Toledo
}

\section{Saint Catherine's Tormentum Rotarum depiction at the church of Saint Sebastian in the Roads in Toledo}

\author{
Adolfo DE MINGO LORENTE \\ Universidad de Castilla-La Mancha \\ mingo.lorente@gmail.com
}

Recibido: $10 / 02 / 2015$

Aceptado: 15/06/2015

\begin{abstract}
Resumen: La iglesia de San Sebastián de las Carreras, uno de los templos más antiguos de Toledo, muy próximo a la primitiva sede del Colegio y Universidad de Santa Catalina (constituida en 1485), conserva sobre uno de sus muros la representación más completa del ciclo iconográfico de la santa doctora que es posible contemplar en la ciudad. Su estado de conservación es muy deficiente, pero permite identificar con claridad varias de las escenas transmitidas por Jacobo de la Vorágine en La Leyenda Dorada, entre ellas la célebre plasmación del martirio con ruedas dentadas.
\end{abstract}

Palabras Clave: San Sebastián de las Carreras, iconografía de Santa Catalina, La Leyenda Dorada, martirio con ruedas dentadas, siglo XVI.

\begin{abstract}
The church of Saint Sebastian in the Roads, one of the oldest temples in Toledo, very close to the old seat of College and University of Saint Catherine (founded in 1485), preserves on its walls the most complete representation of the iconographic system of this saint in this city. Its state of conservation is severely deficient, but allows clearly to identificate several scenes in Jacobo de Voragine's Golden Legend book, from among them the famous martyrdom with toothed wheels.
\end{abstract}

Key Words: Saint Sebastian in the Roads, Saint Catherine's iconography, Golden Legend, martyrdom with toothed wheels, sixteenth century.

Sumario: 1. Características y evolución de las pinturas. 2. Interpretación iconográfica. 2.1. ¿Representación de la disputa con los doctores? 2.2. Santa Catalina en prisión. 2.3. Representación del Tormentum Rotarum, martirio de Santa Catalina. 2.4. ¿El entierro de Santa Catalina? 2.5. Representación individualizada de la santa. 3 . Conclusiones.

$$
* * *
$$

La iglesia toledana de San Sebastián de las Carreras, templo de reducidas dimensiones probablemente construido sobre los restos de la antigua mezquita de AlDabaggin (siglos X-XI), principalmente desarrollado durante la Baja Edad Media y sustancialmente modificado en los siglos XVII y XVIII, ha disfrutado durante la última década de una de sus mejores etapas después de muchos años enfrentándose a un secular abandono. El derrumbe parcial de uno de sus muros a finales de 2004 impulsó la actuación de urgencia por parte del Consorcio de la Ciudad de Toledo, organismo que durante más de dos años asumiría una completa rehabilitación del edificio conforme al proyecto del arquitecto Manuel Urtiaga de Vivar. La empresa encargada de asumir las tareas de consolidación y prospección 
de la iglesia fue Artemon S.A., bajo la supervisión arqueológica de Juan Manuel Rojas Rodríguez-Malo. El resultado de las actuaciones de consolidación y rehabilitación, palpable en las sucesivas campañas de apertura al público del edificio - incluido dentro de las Rutas de Patrimonio Desconocido del Consorcio y sede canónica de la Cofradía Internacional de Investigadores del Santísimo Cristo de la Oliva, además de ocasional sala de exposiciones-, ha permitido dirigir la mirada hacia un pequeño retablo pintado sobre el primer tramo de la actual nave de la epístola, sobre los viejos paramentos del muro.

La superficie pictórica, sumamente deteriorada y parcialmente perdida en las cinco escenas que componen el conjunto, apenas nos deja esbozar una propuesta de identificación iconográfica. Solamente gracias a la fotografía en alta definición pueden apreciarse con claridad detalles como, en la zona inferior de la calle izquierda del retablo, las trazas de un par de ruedas dentadas, el elemento más característico del tormentum rotarum o martirio de las ruedas, una de las escenas más habituales dentro de las representaciones de la mártir Santa Catalina de Alejandría. A lo largo de estas líneas pretendemos ofrecer no solamente una propuesta de interpretación de esta olvidada representación, sino reconstruir el que probablemente sea el ciclo iconográfico más completo sobre la santa doctora que fue titular del convento de la Merced, sobre el cual se construyó en el siglo XIX el palacio de la Diputación, y que ha sido abundantemente figurada de forma individualizada - de cuantos se conservan en Toledo actualmente.

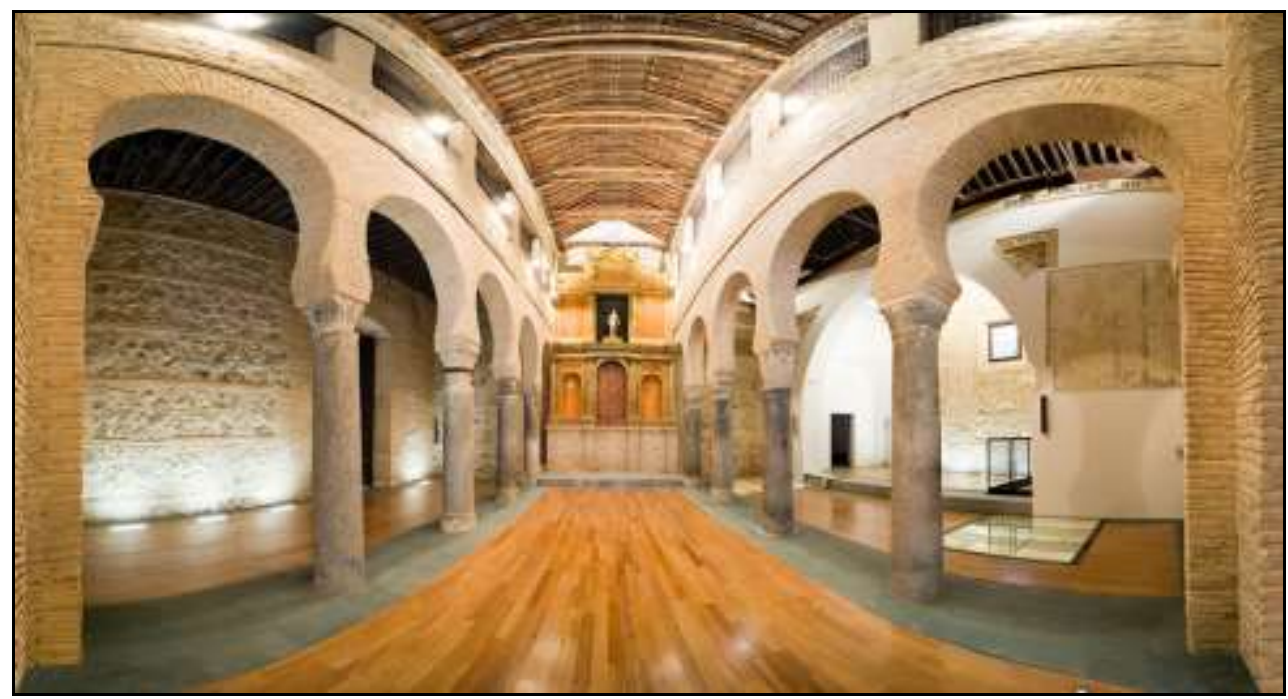

Fig. 1. A la derecha, en el primer tramo de la actual nave de la epístola, panel pintado con el ciclo de Santa Catalina. Iglesia de San Sebastián, Toledo. Fotografía de José María Moreno Santiago.

\section{Características y evolución de las pinturas.}

El ciclo de Santa Catalina en la iglesia de San Sebastián ocupa una porción del muro equivalente al actual primer tramo de la nave por el lado de la epístola. Este emplazamiento, sin embargo, no se corresponde con la articulación interior original del templo, ya que su estructura fue sustancialmente modificada en el siglo XVIII, momento en el que parece probable que las representaciones fueran cubiertas. Es posible, por lo tanto, que este retablo pintado ocupase entonces una posición más relevante. 
El estado en que ha llegado hasta nosotros no permite aportar muchos detalles sobre la ejecución. Se han conservado con cierta nitidez los enmarques separadores de las diferentes escenas, resueltos por medio de cordones y diseños calados típicamente gótico-renacentistas que hacen posible reconocer las intersecciones de un retablo de tres calles, a pesar de la desaparición de grandes áreas de pintura. La composición y dibujo de cada representación, según veremos a continuación, es bastante clara pese a su degradación. No así el acabado final del retablo, pues el cromatismo ha sufrido mucho y apenas si se conservan algunas masas de color parduzcas y rojas, por lo que resulta difícil precisar, en este sentido, si el conjunto fue acabado o bien quedó sin rematar. Sí es posible sostener que los responsables del retablo se preocuparon de respetar, perfilándola mediante una bordura, una lápida que ya no se encuentra en el edificio y que formaba parte de un conjunto que Manuel González Simancas dató entre 1274 y $1309^{1}$.

Esta horquilla, sin embargo, resulta muy anterior a la datación prevista para las pinturas. La Universidad de Santa Catalina, vecina de la iglesia de San Sebastián, dio sus primeros pasos en el año 1485, constituyéndose como institución pontificia en $1520^{2}$. No existe referente alguno relacionado con la santa doctora en el entorno de las humildes Carreras de San Sebastián hasta ese momento ${ }^{3}$. El atuendo del sayón postrado a los pies de las ruedas dentadas, por otra parte, puede situarse en la misma órbita que otras representaciones similares realizadas en las primeras décadas del siglo XVI.

Las pinturas murales de finales del periodo medieval conservadas en la ciudad de Toledo son bastante escasas y han sido poco estudiadas, lo que dificulta cualquier propuesta de identificación de su autor. El conjunto de Santa Catalina en la iglesia de Sebastián, por ejemplo, se encuentra menos desarrollado y ha llegado hasta nosotros en mucho peor estado que las representaciones de Santa Eulalia de Mérida y Santa Julia situadas en el testero de la capilla de los Carriones de la cercana iglesia de San Lucas. Su calidad, por otra parte, es menor en comparación con los restos, también muy degradados, de la capilla de los Illanes de San Román. Las representaciones fueron previsiblemente cubiertas durante la reforma interior que se realizó en San Sebastián en el siglo XVIII, según planteó Ramírez de Arellano en su estudio clásico sobre las parroquias toledanas ${ }^{4}$. Lo cierto es que per-

\footnotetext{
${ }^{1}$ Manuel González Simancas, Toledo. Sus monumentos y el arte ornamental, Madrid, Regina, 1929, p. 238 (facsímil publicado en Valladolid por Maxtor, 2005); 'Ampliaciones y rectificaciones', Boletín de la Sociedad Arqueológica de Toledo, $\mathrm{n}^{\circ}$ 7, 1901, pp. 159-163. Matilde Revuelta Tubino, Inventario artístico de Toledo, Madrid, Centro Nacional de Información Artística, Arqueológica y Etnológica, 1983, vol. I, p. 321.

${ }^{2}$ Para conocer el desarrollo de la antigua Universidad de Toledo, suprimida en 1845 y en la actualidad simbólicamente integrada, con las de Almagro y Sigüenza, dentro de la Universidad de Castilla-La Mancha (UCLM), es posible destacar el estudio póstumo de Luis LORENTE TOLEDO, La Real y Pontificia Universidad de Toledo (siglos XVI-XIX), Ciudad Real, UCLM, 1999.

${ }^{3}$ Julio Porres Martín-Cleto, Historia de las calles de Toledo, Toledo, Ed. Bremen, $4^{\mathrm{a}}$ edición, 2002, vol. I, pp. 331-334, y vol. III, pp. 1105-1107.

${ }^{4}$ Rafael RAMíREZ DE ARELlano, Las parroquias de Toledo, Toledo, Sebastián Ramírez, 1921, pp. 267-270 (existe una edición facsímil publicada en Toledo por el Instituto Provincial de Investigaciones y Estudios Toledanos-IPIET, 1997).
} 
manecieron ocultas hasta que aparecieron a finales del XIX como resultado de una restauración interior del edificio, según González Simancas, que en 1929 las definió como «notables» ${ }^{5}$. El recorrido de estas pinturas a lo largo del siglo XX ha sido muy breve, pudiéndose destacar, a comienzos de los años noventa, un artículo de Fernando Aranda en el cual interpretó equivocadamente las representaciones como un martirio de San Erasmo ${ }^{6}$.

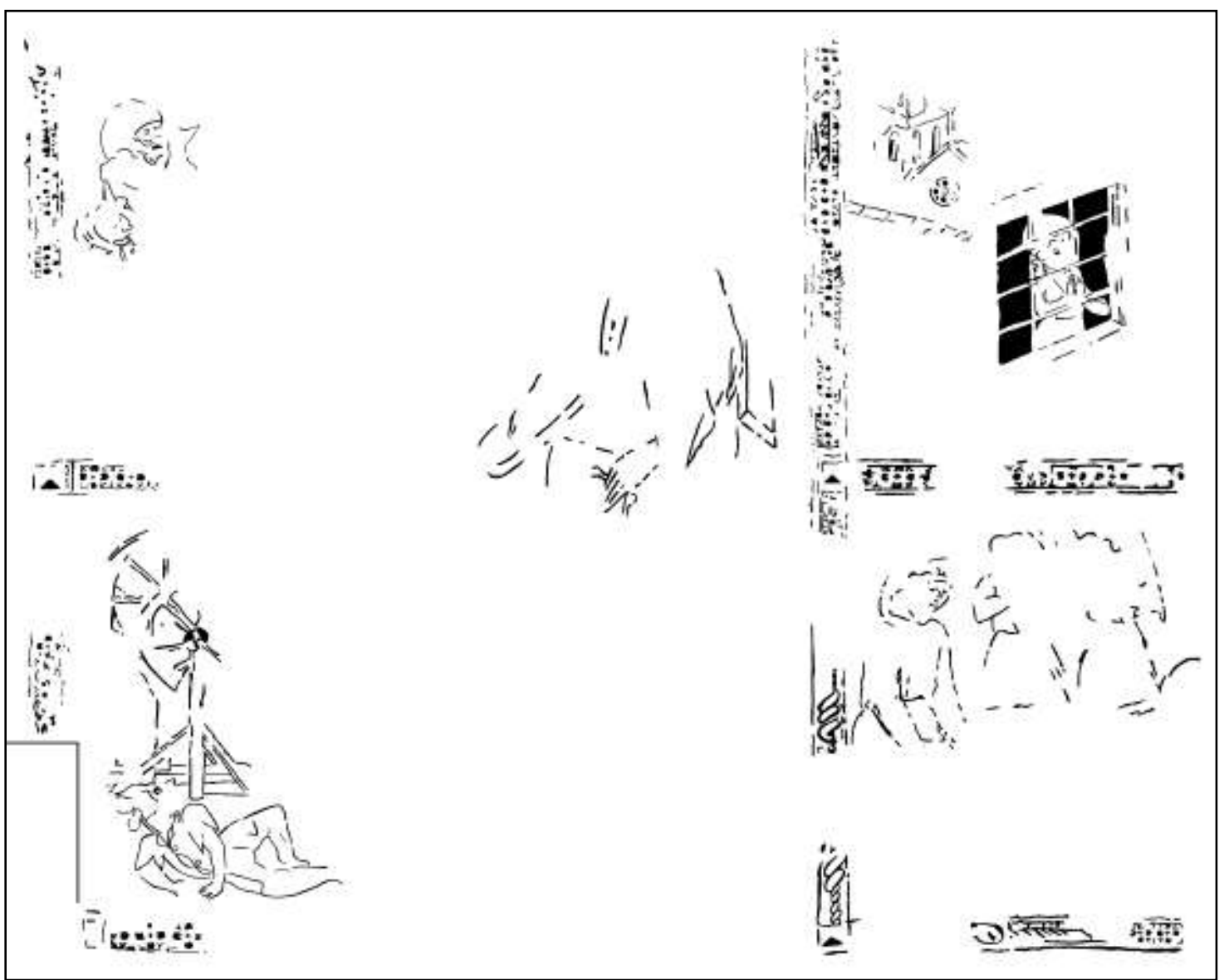

Fig. 2. Croquis con la interpretación del retablo pintado de Santa Catalina, de autor desconocido: Tres calles, completa la central y subdividida en dos escenas las laterales. Interpretación del autor.

\section{Interpretación iconográfica.}

Las representaciones de Santa Catalina de Alejandría fueron muy abundantes durante el periodo medieval, desde el Monte Sinaí (Egipto) hasta las Islas Británicas. El pintor Fernando Gallego (ha. 1440-1507), uno de los representantes más célebres de la escuela gótica castellana, plasmó de forma historiada el ciclo de la santa doctora en varias ocasiones. De uno de los más tempranos, realizado alrededor de 1470 y conservado en el Museo Nacional del Prado, procede precisamente una de las tablas más famosas de toda la pintura medieval española. Las escenas de Santa Catalina a finales de la Edad Media y comienzos del Renaci-

\footnotetext{
${ }^{5}$ GONZÁlEZ SIMANCAS 1929: 238.
}

${ }^{6}$ Fernando ARANDA Alonso, 'La iglesia de San Sebastián. Sede canónica de la Cofradía Internacional de Investigadores', Beresit, n. ${ }^{\circ}$ 4, 1992, pp. 11-32. 
miento fueron abundantísimas, pudiéndose destacar también las versiones que realizaron el llamado 'Maestro de Ávila' y el significativamente denominado 'Maestro de la Leyenda de Santa Catalina', ambos a finales del siglo XV, dentro del panorama castellano.

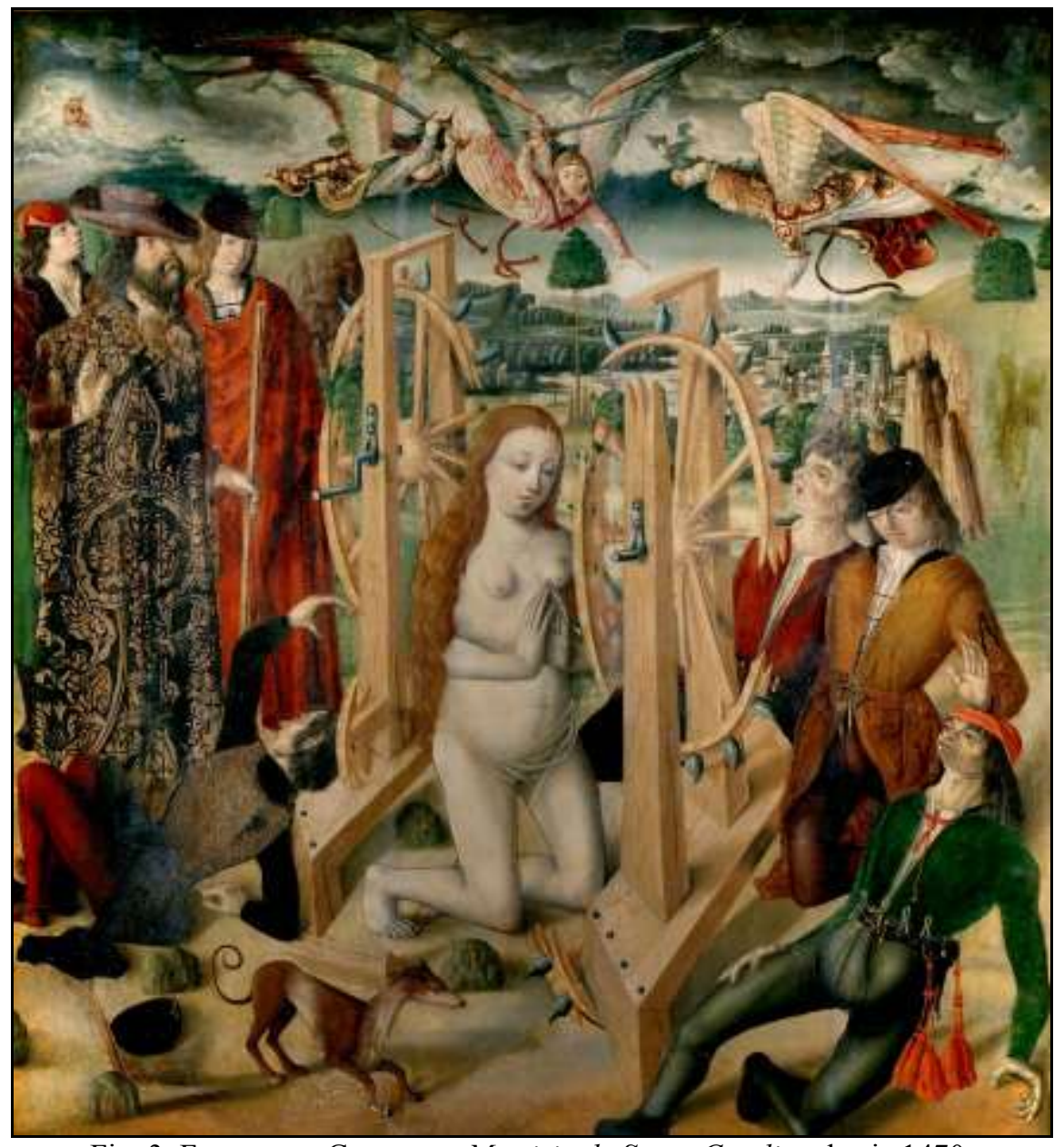

Fig. 3. Fernando Gallego, Martirio de Santa Catalina, hacia 1470. Museo Nacional del Prado.

Como en la versión de Gallego, el retablo con el ciclo de Santa Catalina en San Sebastián está vertebrado en tres calles diferentes, siendo dedicada la central a una representación de cuerpo entero y en pie de la santa doctora. Las laterales se encuentran subdivididas en dos escenas cada una.

\section{1 ¿Representación de la disputa con los doctores?}

La zona superior de la calle lateral izquierda permite reconocer claramente, pese a la gran pérdida de la superficie pictórica, un par de cabezas cuya mirada se dirige hacia el interior de la escena. La más alta y mejor conservada de las dos es la de un anciano barbudo, que mantiene la boca abierta en una especie de asombrada mueca. Va ataviado con una túnica rojiza y se encuentra cubierto con un tocado del mismo color. En una posición ligeramente inferior puede localizarse una segunda testa, en este caso imberbe y dominada por una gran nariz, cuya expresión, al igual que sucede con su compañera, parece haber sido exagerada hasta la caricatura. 
Según La Leyenda Dorada, el compendio de relatos hagiográficos escrito por Santiago de la Vorágine a mediados del siglo XIII, el emperador Maximino (o Maxencio) sometió a la joven virgen Catalina de Alejandría a una disputa teológica en la que tuvo que enfrentarse a medio centenar de filósofos y de la cual salió victoriosa:

«Y durante la controversia refutó con tal sabiduría, rapidez, contundencia y con argumentos tan claros los asertos de sus contrarios y las objeciones de sus oponentes, que llegó un momento en que los oradores, acorralados por ella, quedaron atónitos y se vieron obligados a guardar silencio y a permanecer como mudos, porque ninguno de ellos sabía contestar a las preguntas de Catalina ni replicar a las respuestas que ella misma daba»?

La cabeza del anciano y la de su acompañante podrían identificarse como dos de estos doctores, indignados al ser refutados sus argumentos por la joven. Es muy probable que en la zona perdida de esta escena apareciera la propia Catalina de Alejandría, que a finales de la Edad Media y el siglo XVI era a menudo representada en actitud de realizar el cómputo digital, es decir, enumerando ante los ancianos sus postulados sobre la existencia de Dios con los dedos de sus manos extendidos ${ }^{8}$.

\subsection{Santa Catalina en prisión.}

La Leyenda Dorada transmite a continuación que la santa, tras su negativa a contraer matrimonio con el césar romano, fue torturada con escorpiones «cadenas de hierro acabadas en afilados garfios»-y encerrada en una mazmorra durante doce días, privada de alimentos. En la escena superior derecha de las pinturas de San Sebastián es posible, precisamente, identificar una figura femenina, tocada la cabeza con un nimbo de santidad, que junta sus manos en oración tras los barrotes de una ventana.

La deficiente conservación de la zona impide identificar más elementos que las arquitecturas de una ciudad en último término, especialmente un gran edificio con un rosetón central. No han quedado indicios de otras figuras que pudieron formar parte de la escena conforme a lo que recogen las fuentes hagiográficas, como la esposa del césar - a quien Santa Catalina convirtió al cristanismo desde la mazmorra - o la paloma que alimentaba a la santa durante su encierro.

7 - Santiago DE LA VorÁgine, La Leyenda Dorada, Madrid, Alianza Editorial, Col. Alianza Forma, 12. ${ }^{\text {a }}$ edición, 2005, vol. II, pp. 765-774.

${ }^{8}$ O. ChomentovsKaiA, 'Le comput digital. Histoire d'un geste dans l'art de la Renaissance italienne', Gazette des Beaux-Arts, n. ${ }^{\circ}$ 20, 1938, pp. 157-172. 


\subsection{Representación del Tormentum rotarum, martirio de Santa Catalina.}

Otros dos elementos permiten identificar, en la escena inferior de la calle lateral izquierda, el célebre martirio (o, más correctamente, la milagrosa supervivencia al martirio) de Santa Catalina. En primer lugar, se trataría de las dos ruedas de cuchillos que sus verdugos hacían girar contra el cuerpo de la santa mártir y que así describen los esbirros del emperador en La Leyenda Dorada:

«De aquí a tres días podremos tener preparadas cuatro ruedas cuajadas de agudísimos clavos y de pequeñas sierras dentadas. Será un instrumento de tortura verdaderamente horroroso; si lo aplicamos a esta doncella su cuerpo en poco rato quedará acribillado y hecho trizas por los pinchazos de los garfios y por las sajaduras de las sierras» ${ }^{9}$.

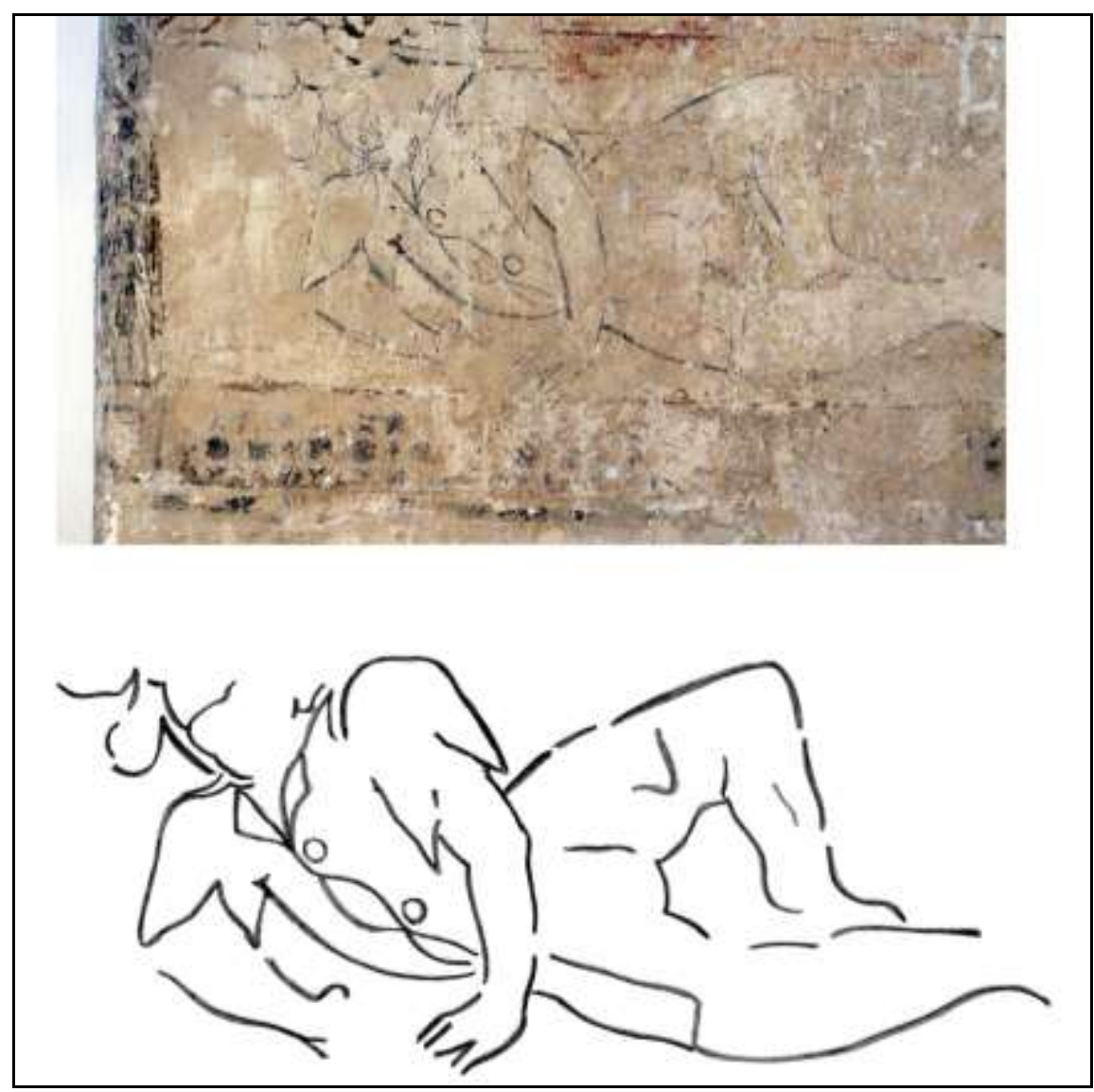

Fig. 4. Detalle del sayón postrado a los pies de las ruedas de Santa Catalina, en la escena inferior de la calle lateral izquierda. Fotografía con los restos de pintura y croquis. Interpretación del autor.

El otro elemento reconocible dentro de esta escena es el cuerpo de uno de estos sayones - del cual es posible apreciar los detalles de su indumentaria, especialmente mangas y abotonaduras-, precipitado en el suelo tras la intervención de los ángeles que detuvieron y destrozaron el instrumento de tortura. La mala conservación impide conocer si las representaciones angélicas fueron incluidas, lo cual era habitual en aquel momento, al igual que el cuerpo de la santa o la escena

${ }^{9}$ VORÁGINE, 2005 (vol. II): 770. 
de su decapitación, normalmente yuxtapuesta con la del tormento de las ruedas. Lo cierto es que la morfología del instrumento de tortura, asegurado por medio de un caballete sobre varios escalones, resulta similar a otras ruedas de Santa Catalina representadas durante el siglo XV en el mismo contexto, y no solamente por Gallego y sus seguidores.

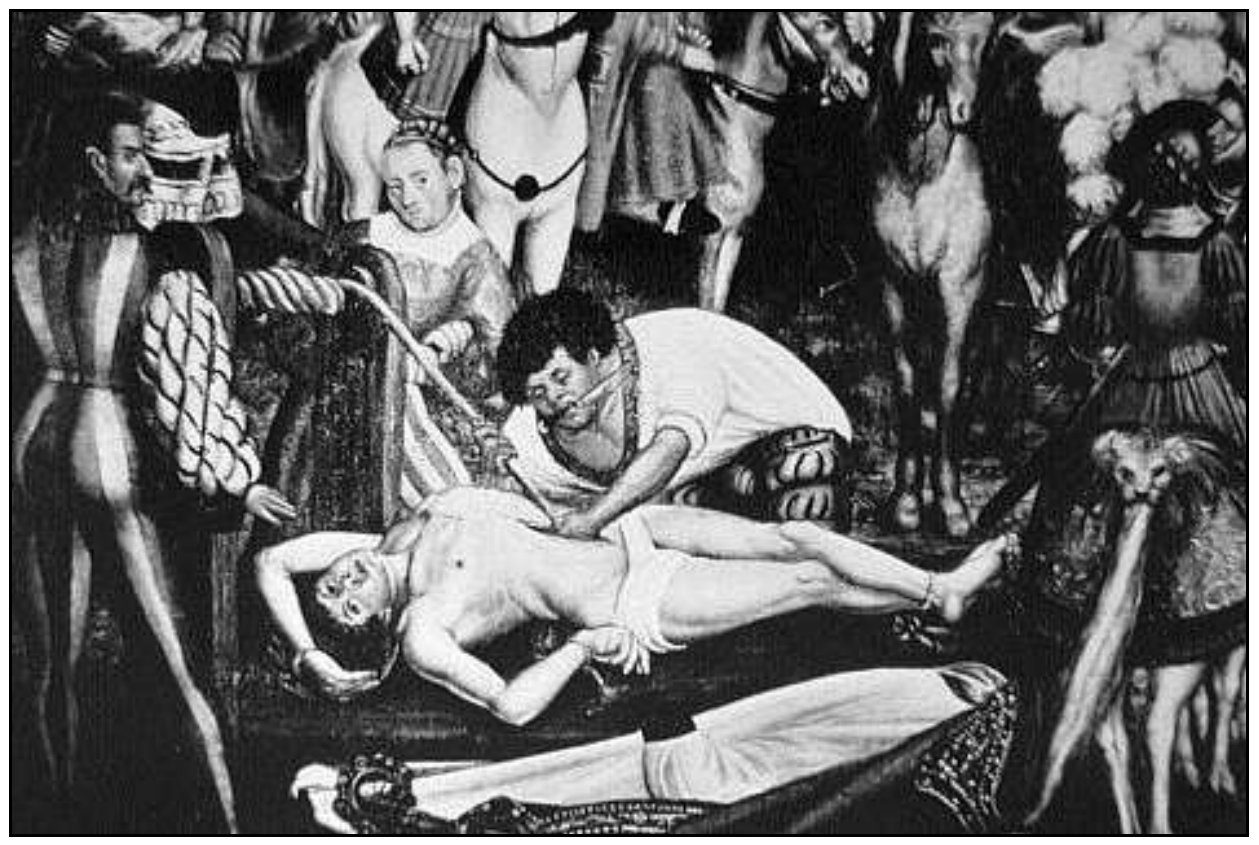

Fig. 5. SATRAPITANUS, Martirio de San Erasmo, 1516.

Staatsgemäldesammlung, Aschaffenburg (Alemania).

En la ciudad de Toledo, la rueda dentada no solamente ha llegado hasta nuestros días en abundantes representaciones individualizadas de Santa Catalina que fueron realizadas durante esa etapa, sino también en uno de los cuarteles que componen el escudo de la Universidad de Castilla-La Mancha ${ }^{10}$. Un relieve con características similares apareció esculpido en el brocal de un pozo durante las excavaciones realizadas en el aparcamiento del Seminario Metropolitano, a escasa distancia de San Sebastián de las Carreras, durante la primavera de 2004, y es posible contemplar el mismo motivo entre los vítores plasmados por antiguos graduados sobre los muros de la Catedral a la altura de la Plaza Mayor, frente al Teatro de Rojas. Esta íntima vinculación entre la devoción a Santa Catalina de Alejandría plasmada en el retablo de San Sebastián y la antigua Universidad de Toledo, por tanto, impide seguir sosteniendo la hipótesis de que las dos ruedas pintadas en este retablo fuesen en realidad una representación del cabestrante con el que fue martirizado San Erasmo ${ }^{11}$.

\footnotetext{
${ }^{10}$ VV.AA., Ciento cincuenta aniversario del IB El Greco. Fondos históricos del IB El Greco, Toledo, Junta de Comunidades de Castilla-La Mancha, 1996, p. 16. La rueda de Santa Catalina aparece recurrentemente representada en los diferentes sellos históricos de la Universidad de Toledo, cuyos herederos a partir de 1845 fueron el Instituto Provincial de Enseñanza y el actual I.E.S. El Greco, a cuya colección artística está dedicada esta publicación.
}

${ }^{11}$ Recogemos a continuación la descripción exacta formulada por Aranda Alonso: «Durante el siglo XIV debió realizarse un retablo mural pintado al fresco, que parece ser representaba en Eikón Imago 8 (2015/2) $\quad$ ISSN-e 2254-8718 206 


\section{4 ¿El entierro de Santa Catalina?}

La representación de tres ángeles en pie, más una cuarta figura yacente de la que apenas se insinúa el nimbo, permite pensar en el traslado de los restos de la santa doctora o el entierro de los mismos conforme al relato de Simeón Metafrasto - en el que eran ángeles, y no monjes, quienes dieron sepultura a la mártir-, recogido en el siglo XIII en La Leyenda Dorada ${ }^{12}$. La posición del ángel izquierdo, un tanto flexionada sobre el suelo, como si estuviera introduciendo el cuerpo en el interior de un sepulcro, apoya esta última interpretación, la cual era planteada de manera muy similar en aquellos momentos por artistas como Pedro Be1lo, discípulo de Fernando Gallego, en la Catedral de Salamanca ${ }^{13}$. No es posible conocer a priori si el artista representó la cabeza de Santa Catalina separada de su cuerpo tras la decapitación de la mártir, pero sí defender que este tema es con el que finaliza el ciclo historiado, pues se trata de la última escena del retablo.

\subsection{Representación individualizada de la santa.}

Los pocos restos de la representación central, mejor conservada en la zona intermedia, apenas si dejan identificar la mano, el antebrazo y algunos detalles del vestido de una figura situada junto a una pequeña ventana. Las similitudes con respecto a imágenes parecidas dentro de la retablística tardomedieval hacen suponer que la santa titular estuviese acompañada de sus distintivos iconográficos más habituales, como la rueda de su martirio - entera o fragmentada - o la espada con que finalmente murió decapitada. Esta opción parece la más probable, pues es posible apreciar indicios de los gavilanes de una empuñadura entre los dedos del personaje.

La desaparición de la mitad inferior de esta calle no permite precisar si Santa Catalina fue representada imponiéndose sobre una cabeza coronada y humillada por esa supuesta espada, fórmula representativa bastante común (y que es posible encontrar, en el Museo de Santa Cruz, en piezas como una tabla con la Virgen de Monserrat con Santa Catalina y en una Misa de San Gregorio que realizó Berruguete).

una de sus escenas al martirio de San Erasmo, porque tenía en primer término un hombre tendido en el suelo, y por encima un tronco con dos grandes ruedas con las que le destrozaban los intestinos». ARANDA, 1992: 25. Subrayamos la analogía entre ambas fórmulas de representación mostrando un martirio de San Erasmo cronológicamente cercano al retablo pintado de la iglesia de San Sebastián: fue realizado por el pintor Heinrich Vogtherr El Viejo (1490-1556), también conocido como Heinrich Satrapitanus, y se conserva en la Staatsgemäldesammlung de Aschaffenburg (Alemania).

${ }^{12}$ Louis REAU, Iconografía del arte cristiano, Barcelona, Ediciones del Serbal, 2a edición, 2001, vol. III, pp. 282-283. VORÁGINE, 2005 (vol. II): 772.

${ }^{13}$ Sin necesidad de abandonar Toledo, en el terreno de la escultura, sería posible destacar también el entierro de Santa Catalina en la puerta de la Catedral que lleva el nombre de la santa (y que comunica el interior del templo con el claustro). Los ángeles depositan el cuerpo en el interior del sepulcro en esta representación, situada en el capitel del parteluz y cuya disposición resulta similar a la del retablo de San Sebastián. Una descripción de esta puerta fue recogida por Sixto Ramón PARro, Toledo en la mano, Toledo, Severiano Fando, 1857, vol. I, pp. 664 y ss. 


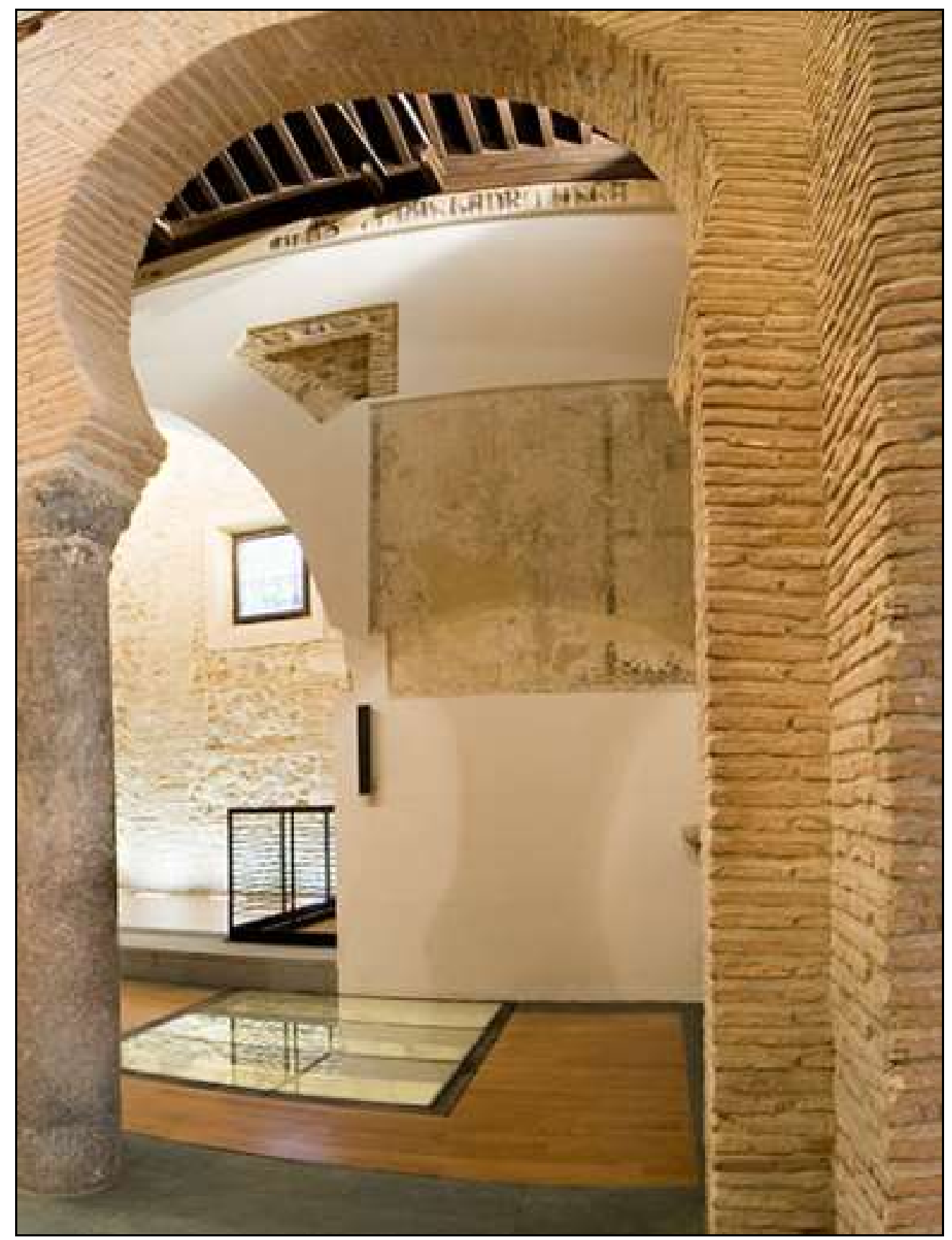

Fig. 6. Panel pintado con el ciclo de Santa Catalina. Iglesia de San Sebastián, Toledo. Detalle de la Fig. 1 (Fotografía de José María Moreno Santiago).

\section{Conclusiones.}

La escasez de estudios sistemáticos sobre iconografía medieval en Toledo impide confirmar la dimensión exacta de este pequeño retablo en un contexto más amplio. Son abundantes las manifestaciones artísticas dedicadas a la santa doctora en la ciudad, pero se trata de representaciones individualizadas, no de ciclos iconográficos completos. La llegada del Renacimiento (especialmente a partir del Concilio de Trento y la necesidad de una semántica artística mucho más directa) traería consigo un punto de inflexión en la manera de representar a la santa. Conforme vaya avanzando el siglo XVI, los ciclos sobre Santa Catalina de Alejandría tenderán a ir desapareciendo para convertirse en escenas únicas, como las difun- 
didas en el ámbito alemán a partir de conocidos grabados de Durero y Cranach el Viejo. Ejemplo de síntesis, en el terreno de la escultura y ya en una fecha tan tardía como el tramo final del siglo XVIII, sería la Santa Catalina del escultor académico José Antonio Finacer que se conserva en el patio del Museo de Santa Cruz y que procede del desaparecido convento de Mercedarios Calzados, en cuyo solar se levantó en el XIX el palacio de la Diputación.

La tardía aparición de la leyenda de los Desposorios místicos de Santa Catalina a finales de la Edad Media - la cual no aparece reflejada en la primera redacción de La Leyenda Dorada, sino en una traducción inglesa de $1438^{14}$ —, para finalizar, competirá a menudo con la escena martirial desde la primera mitad del siglo XVI, siendo representada por artistas como Correggio, Tiziano y Tintoretto, entre otros.

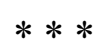

\section{Bibliografía}

ARANDA Alonso, Fernando, 1992, 'La iglesia de San Sebastián. Sede canónica de la Cofradía Internacional de Investigadores', Beresit, n. ${ }^{\circ} 4$, Toledo, Cofradía Internacional de Investigadores del Santo Cristo de la Oliva, pp. 11-32.

ChomentovskaiA, O., 1938, 'Le comput digital. Histoire d'un geste dans l'art de la Renaissance italienne', Gazette des Beaux-Arts, París, no 20, pp. 157172.

GonZÁlez SimanCAS, Manuel, Toledo. Sus monumentos y el arte ornamental, Madrid, Regina, 1929.

GONZÁlEZ SimANCAS, M., 1901, 'Ampliaciones y rectificaciones', Boletín de la Sociedad Arqueológica de Toledo, n. ${ }^{\circ}$ 7, Toledo, pp. 159-163.

LORENTE TOLEDO, Luis, La Real y Pontificia Universidad de Toledo (siglos XVIXIX), Ciudad Real, UCLM, 1999.

PARRO, Sixto Ramón, Toledo en la mano, Toledo, Severiano Fando, 1857.

Porres Martín-Cleto, Julio, Historia de las calles de Toledo, Toledo, Ed. Bremen, 4. ${ }^{\mathrm{a}}$ edición, 2002.

RAMíREZ DE ARELLANO, Rafael, Las parroquias de Toledo, Toledo, Sebastián Ramírez, 1921.

REAU, Louis, Iconografia del arte cristiano, Barcelona, Ediciones del Serbal, $2^{\mathrm{a}}$ edición, 2001.

\footnotetext{
${ }^{14}$ REAU, 2001 (vol. III): 274. El gran especialista francés en iconografía planteó que la proliferación de este tema tiene su origen en una traducción literal del episodio en el que Santa Catalina espetó al emperador que no podía desposarse con él por ser novia de Cristo, una expresión habitual dentro de la literatura hagiográfica. «También es posible que la fuente de esta leyenda sea, como suele suceder, un despropósito 'óptico' derivado de las imágenes en que la santa era representada con una rueda, instrumento de su martirio. Esa rueda, a veces minúscula, habría sido confundida con un anillo de compromiso a causa de sus pequeñas dimensiones», una hipótesis que merece ser tenida en cuenta al apreciar el tamaño de la rueda dentada que porta la santa en algunas representaciones muy anteriores al siglo XVI, momento que nos ha ocupado principalmente.
} 
Adolfo DE Mingo LoRENTE, La representación del Tormentum Rotarum de

Santa Catalina en la iglesia de San Sebastián de las Carreras de Toledo

Revuelta Tubino, Matilde, Inventario artístico de Toledo, Madrid, Centro Nacional de Información Artística, Arqueológica y Etnológica, 1983.

VorÁGINE, Santiago de la, La Leyenda Dorada, Madrid, Alianza Editorial, Col. Alianza Forma, 12. ${ }^{\mathrm{a}}$ edición, 2005.

VV.AA., Ciento cincuenta aniversario del IB El Greco. Fondos históricos del IB El Greco, Toledo, Junta de Comunidades de Castilla-La Mancha, 1996. 